\title{
Comparing selectivity of a standard and turned mesh T90 codend during towing and haul-back
}

\author{
Niels MAdSEN ${ }^{\mathrm{a}}$, Bent Herrmann, Rikke Petri FrandSEn and Ludvig Ahm Krag \\ DTU Aqua, National Institute of Aquatic Resources, North Sea Science Park, 9850 Hirtshals, Denmark
}

Received 17 January 2012; Accepted 11 June 2012

\begin{abstract}
In this study, we compared the size selectivity of a T90 codend (netting turned by 90 degrees) with that of a standard codend made of similar netting. Sea trials were conducted in a Norway lobster directed fishery in the KattegatSkagerrak area, where there is a need for improved selectivity because of a severe discard problem. The codends were tested by fishing simultaneously with them in a twin trawl rig. Codend covers mounted with Minisamplers were used, which made it possible to catch individuals escaping during towing and haul-back separately. Herein we proposed a model to assess the sequential selection during towing and haul back. This model takes into account the parameter $C_{\text {tow }}$, which can be interpreted as the proportion of fish that comes into contact with the codend meshes during towing and, thereby, has a chance of escape. Compared to the standard codend, the $T 90$ codend retained fewer Norway lobster both below and above the legal minimum landing size ( $40 \mathrm{~mm}$, cephalothorax length), thereby causing a reduction of commercial catch. The difference was mainly due to a significantly higher escape rate during towing for the $T 90$ codend. For plaice below minimum landing size $(27 \mathrm{~cm})$, the retention was slightly but significantly higher for the $T 90$ codend compared to the standard codend. A model developed for both codends showed that not all plaice are able to attempt escapement during the towing process. For cod, the results indicated an increased $L 50$ (the length at which 50\% of this species is caught) for the $T 90$ codend, but the effect was not statistically significant, probably due to the limited number of cod retained during the sea trials. The results demonstrated that, for all three species, a significant proportion did escape during haul-back in both codends.
\end{abstract}

Keywords: Discard / Turned mesh codend / Demersal trawl / Size selectivity / Norway lobster /Nephrops norvegicus / Gadus morhua / Pleuronectes platessa / Kattegat

\section{Introduction}

Norway lobster (Nephrops norvegicus) directed trawl fisheries are commercially important in many areas in the North East Atlantic. However, the relatively small mesh sizes used to retain Norway lobster cause high bycatch rates of juvenile individuals in many areas. Due to regulations on minimum landing size $(M L S)$ and size-related value of the fish, this results in generally high discard rates in European Norway lobster fisheries (Catchpole and Revill 2008), which could be reduced by improved selectivity patterns. The Kattegat-Skagerrak area is characterized by high discard rates (Krag et al. 2008; Valentinsson and Ulmestrand 2008; Frandsen et al. 2009; Feekings et al. 2012), the selectivity of the standard $90 \mathrm{~mm}$ diamond mesh codend used in this area is poor (Krag et al. 2008; Frandsen et al. 2009), and the cod stock in Kattegat is in a critical state (Madsen and Valentinsson 2010).

T90 codends, in which standard diamond mesh netting is turned 90 degrees (Fig. 1), could potentially could improve size selective properties compared with traditional codends

\footnotetext{
a Corresponding author: nm@aqua.dtu.dk
}

made of the same netting. In the traditional netting orientation of the standard codend, the mesh resistance to opening tends to close the meshes. Turning the netting 90 degrees hampers this mechanism, which would provide a more open mesh that might allow more small individuals to escape. The netting knot size, defined by the knot type and twine characteristics, may also contribute to the benefits provided by turning the netting by 90 degrees (Herrmann et al. 2007). Hence, the more open $T 90$ meshes would improve the selectivity of the fishing gear, especially for species with a cross section that is more round than flat, such as Norway lobster (Frandsen et al. 2010a) and cod (Herrmann et al. 2009). As standard conventional netting can be used, a $T 90$ codend is a very simple way to potentially improve the size selectivity of the fishing gear. Furthermore, compared to square mesh codends that are often used to improve codend selectivity, the $T 90$ codend maintains the flexibility, which makes handling easier when catch volume is large.

T90 netting has been the focus of increased scientific interest in recent years (ICES 2010, 2011), and was included in the legislation for the Baltic Sea cod (Gadus morhua) fishery in 2006 (Madsen 2007). Commercial experimentation and use 
(a)

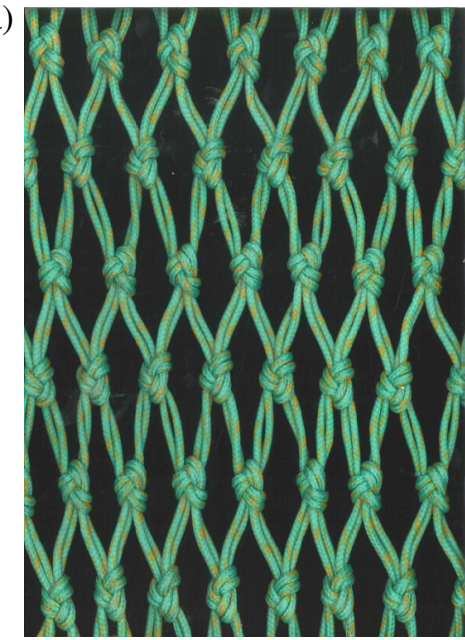

(b)

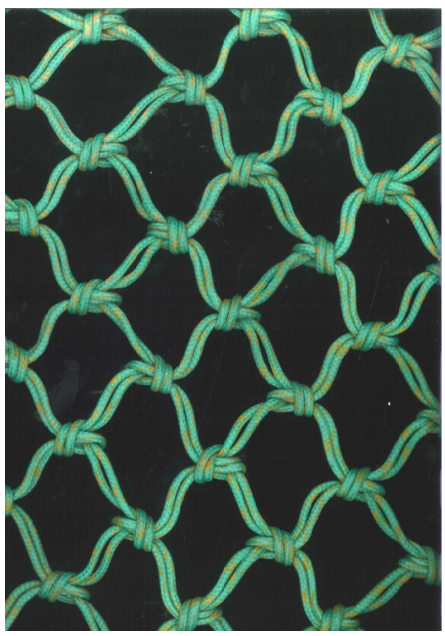

Fig. 1. Above: (a) the standard netting used. Below: (b) the turned mesh $T 90$ netting used. These photographs were taken after the sea trials.

of $T 90$ netting in both demersal and pelagic gear has also been growing (ICES 2011). A theoretical simulation-based study estimated that a $50 \%$ reduction in codend circumference, which was introduced in the Baltic Sea when the T90 codend was implemented in legislation, would contribute considerably to an overall increase of $L 50$ ( $50 \%$ retention length) (Herrmann et al. 2007). This finding suggests that when evaluating the effect of $T 90$ meshes on selectivity, it is important that other codend design parameters are not changed at the same time. Results of a recent experiment showed that $T 90$ netting can improve the size selectivity of Baltic cod compared with a standard codend made of similar netting (Wienbeck et al. 2011). For other fisheries and species, however, little is known about the selective properties of $T 90$ codends compared to a standard codend.

A substantial proportion of escapes may take place during the haul-back operation, i.e., when the trawl is hauled from the sea bed to the surface and onboard the fishing vessel (Madsen et al. 2008; Grimaldo et al. 2009). This is an important aspect of the selection process because it likely causes additional stress and physical damage to these escapees compared with those that escape during towing. The fishing gear's ability to release individuals efficiently during towing rather than haul-back is, therefore, an important aspect, and the $T 90$ codend may perform better than the standard codend because the meshes are expected to stay more open. Consequently, it is important to determine whether the $T 90$ codend facilitates release of more undersized fish and Norway lobster than the standard codend during the towing process at the sea bed, or whether the main difference in their selective properties is related to the haul-back process.

The main objective of this study is to compare the size selective properties of a T90 codend with those of a similar standard codend without other design changes. In particular, we wanted to investigate whether a $T 90$ codend could be a simple way to improve size selectivity in the Norway lobster directed fishery, where the selectivity is generally poor. We focused on three commercially important species categories with different morphologies and behaviours (roundfish, flatfish, and Crustaceans). To meet the main objective we used a method that made it possible to evaluate selectivity during towing and haulback for two codends fished simultaneously. Furthermore, we developed a selectivity model that exploited these additional data and allowed assessment of the sequential selection during towing and haul back as well as an estimation of the proportion of fish that actually came into contact with the codend meshes during towing and thereby had a chance of escape.

\section{Methods}

\subsection{The fishing area, vessel, and trawl}

The sea trials were conducted in the Northern Kattegat and the Skagerrak from 13 to 21 September 2007, fishing on commercial fishing grounds. The commercial stern trawler Mette-Amalie (RS 30) was used, which is $20 \mathrm{~m}$ long and powered by a $386 \mathrm{~kW}$ engine. Two identical combined fish and Norway lobster trawls with an inside nominal mesh size of $100 \mathrm{~mm}$ and 460 meshes in the circumference of the fishing circle were fished in a twin trawl rig. A three warp towing system with a $550 \mathrm{~kg}$ chain clump and two $194 \mathrm{~cm}$ Welle otter boards was used to tow the gear. The towing rig behind the otter boards consisted of $94 \mathrm{~m}$ single sweeps. Warp length was from around $220 \mathrm{~m}$ to $470 \mathrm{~m}$ depending on depth.

\subsection{Test codends}

The two codends tested were made of the same nominal $90 \mathrm{~mm}$ (inside mesh size) $4 \mathrm{~mm}$ double polyethylene (PE) netting (Fig. 1). Both codends were constructed by the same net maker. They were 49.5 meshes long and had 46 open meshes in circumference in each of the two panels and 4 meshes in both selvedges, giving a total of 92 open meshes. The codends were attached to a $3 \mathrm{~m}$ (stretched) long diamond mesh extension made of the same netting as the codends and having the same number of meshes in circumference. This was done to enable handling of the codend when emptying the catch through a zipper in the cover and into the pounder. Furthermore, it kept the front of the cover, which was attached in front of this section, well clear of the codends. 

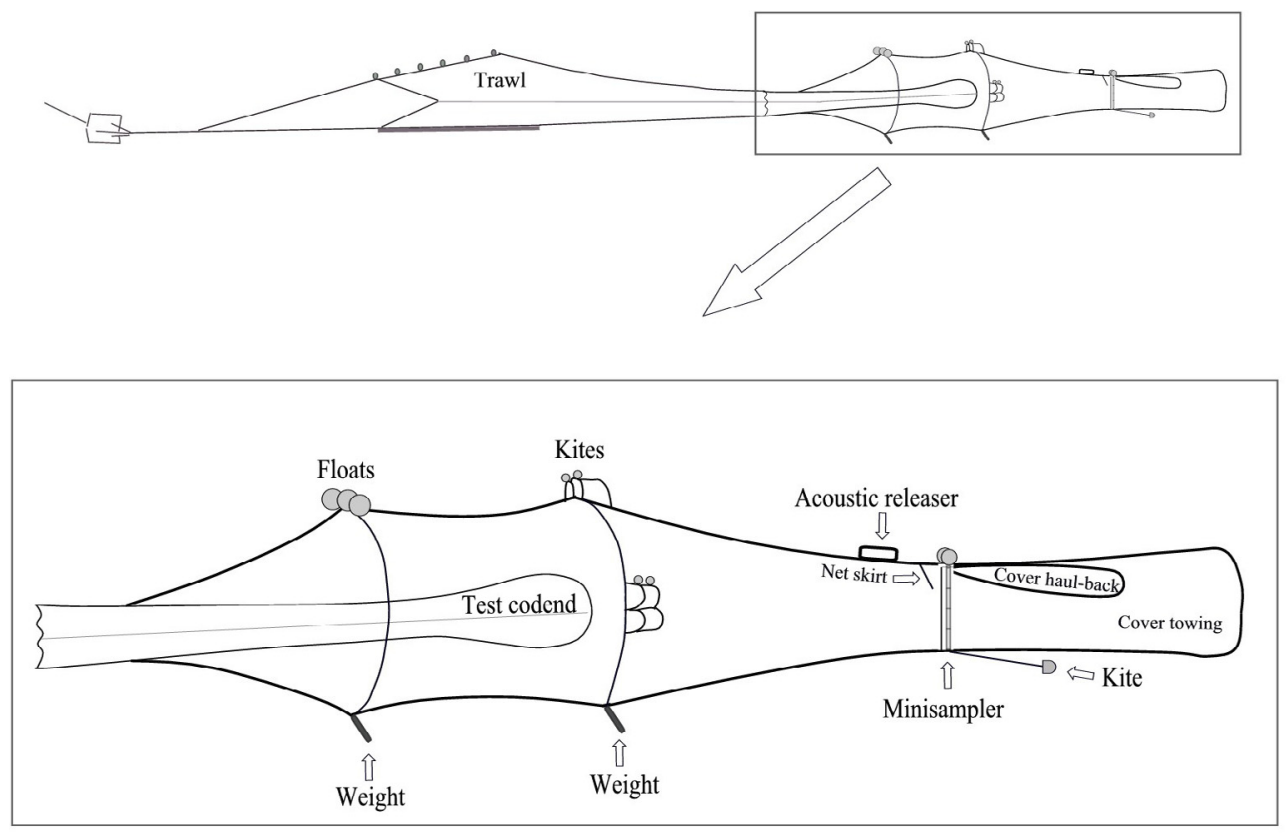

Fig. 2. Illustration of the codend cover technique.

\subsection{Method for collecting escaping fish}

The selectivity of the codends was estimated using the covered codend method described by Madsen et al. (2001). Two identical covers were made (Fig. 2). To limit the visual contrast, the cover netting in the region around the codend was made of thin $(1.2 \mathrm{~mm})$ white knotted Dyneema twine mounted in a square mesh position. Covers were attached to the trawl extensions, and the aft part of the covers was made of PE netting $(1.8 \mathrm{~mm})$ with a nominal mesh size of $40 \mathrm{~mm}$. A combination of kites, chains, and floats was used to keep the covers free of the test codends (Madsen et al. 2001). A "Minisampler" unit was attached to each cover (Madsen et al. 2012), making it possible to take two separate cover samples (Fig. 2). This system, developed by our research group, was tested at full scale in a flume tank (Hirtshals, Denmark) prior to the sea trials. We wanted to be able to discriminate between escape during towing and escape during haul-back. This is because the chance of survival for fish escaping during towing is expected to be higher. The bags of the Minisamplers were released one by one immediately before haul-back to sample escapees during the well defined period from beginning of hauling to the point when the codend was on the deck. The order of release of the two Minisamplers (one on each codend) was changed before each haul-back to compensate for a limited delay (about $30 \mathrm{~s}$ ). The codends were interchanged midway through the experiment (after 8 hauls) to compensate for a potential effect of the position of the codend in the twin trawl rig.

\subsection{Measurements}

Operational conditions were recorded for each haul. Depth, speed, and sea state were recorded at the beginning and end of the haul and average values were calculated. The approximate sea state was estimated by eye, using fixed points at the side of the vessel as a scale.

The total codend and cover catches were weighed separately using a crane scale on deck, and the weight of the netting was subtracted. The catches for each of the three compartments of each side then were handled and measured separately. All cod were measured. All plaice (Pleuronectes platessa) were measured except for one compartment from one T90 haul, which was subsampled (62\% measured). Cod and plaice were measured to the nearest $\mathrm{cm}$ below. All Norway lobster were measured in $60 \%$ and $67 \%$ of the fractions for the standard and $T 90$ codends, respectively. For the remaining fractions, catches were large and these were subsampled. The subsampling ratio for each fraction was $4-35 \%$. The cephalothorax length of Norway lobster was measured to the nearest $\mathrm{mm}$ below using an electronic calliper. In the subsequent analysis, $0.5 \mathrm{~cm}$ was added to the length classes of fish and $0.5 \mathrm{~mm}$ was added to all length classes of Norway lobster.

Mesh size was estimated based on 100 measures of each codend when dry, before the sea trials, and when wet, midway through the experiment (after haul 8) and after the sea trials. All mesh measurements were made using an OMEGA gauge (Fonteyne et al. 2007).

\subsection{Development of a sequential selectivity model}

We used a three-compartment experimental design (codend cover towing, codend cover haul-back, and test codend) for each side in the twin rig, for each haul, and for each length class $(l)$. Thus, we obtained data on the number of fish (and Norway lobster) in the cover tow $\left(n c t_{l}\right)$, in the cover haulback $\left(n c h_{l}\right)$, and in the test codend $\left(n t_{l}\right)$. Assuming that the 
fate of a fish is independent of that of any other fish, the number of individuals of a specific length class $l$ present in the three compartments could be modelled by a multinomial distribution with length-dependent probabilities for escapement during the towing process $\left(e_{\text {tow }}(l)\right)$ and during the haul-back operation $\left(e_{\text {haul-back }}(l)\right)$ and for being retained in the test codend in the total process $\left(r_{\text {total }}(l)\right)$.

For the fish that actually attempted to escape through the codend meshes during the towing process, we assumed that the length-dependent retention likelihood could be described by a logit model with the parameters $L 50_{\text {tow }}$ and $S R_{\text {tow }}$, where $L 50$ is the $50 \%$ retention length and $S R$ is the selection range (L75-L25). Our model takes into account the parameter $C_{\text {tow }}$, which can be interpreted as the proportion of fish that comes into contact with the netting during towing and thereby has a chance of escape. $C_{\text {tow }}$ was modelled by a single lengthindependent number ranging between 0.0 and 1.0. A value of 1.0 would mean that every individual made contact with the codend meshes during towing and had a chance to escape through them. $C_{\text {tow }}$ would be less than 1.0 if some fish did not come in contact with the netting, which might be caused by fish not trying to escape. Including a parameter for the proportion of fish that comes into contact with the netting during haul-back $\left(C_{\text {haul-back }}\right)$ in the model led to a poorer fit of the model when evaluating it based on AIC values (Akaike 1974).

For the fish remaining in the codend after the towing process was completed, we assumed that the likelihood that they would still be in the codend after completion of the haul-back process could be described by a logit model with parameters $L 50_{\text {haul-back }}$ and $S R_{\text {haul-back }}$. On a haul-by-haul basis, the parameters $C_{\text {tow }}, L 50_{\text {tow }}, S R_{\text {tow }}, L 50_{\text {haul-back }}$, and $S R_{\text {haul-back }}$ can, in principle, be estimated simultaneously by maximizing the corresponding likelihood function for the assumed model. Thus, function (1) can be minimised, which is equivalent to maximizing this likelihood:

$$
\begin{gathered}
-\sum_{l}\left[n t_{l} \times \ln \left(r_{\text {total }}(l)\right)+n c t_{l} \times \ln \left(e_{\text {tow }}(l)\right)\right. \\
\left.+n c h_{l} \times \ln \left(e_{\text {haul-back }}(l)\right)\right] .
\end{gathered}
$$

The summation is performed over the length classes. The length-dependent likelihood functions are given by:

$$
\begin{aligned}
e_{\text {tow }}(l)= & C_{\text {tow }} \times\left(1.0-\operatorname{logit}\left(l, L 50_{\text {tow }}, S R_{\text {tow }}\right)\right) \\
e_{\text {haul-back }}(l)= & \left(1.0-\operatorname{logit}\left(l, L 50_{\text {haul-back }}, S R_{\text {haul-back }}\right)\right) \\
& \times\left(1.0-e_{\text {tow }}(l)\right) \\
r_{\text {total }}(l)= & 1.0-e_{\text {tow }}(l)-e_{\text {haul-back }}(l)
\end{aligned}
$$

where:

$$
\operatorname{logit}(l, L 50, S R)=\frac{\exp (\ln (9) \times(l-L 50) / S R)}{1.0+\exp (\ln (9) \times(l-L 50) / S R)} .
$$

The data were analysed using the computer software SELNET (developed by the second author of the present paper) to estimate the parameter values $\left(C_{\text {tow }}, L 50_{\text {tow }}, S R_{\text {tow }}, L 50_{\text {haul-back, }}\right.$ and $S R_{\text {haul-back }}$ ) describing the average process for each codend design (standard and T90) following the estimation procedure described in Sistiaga et al. (2010). This estimation procedure involves pooling the raised data for all hauls and using equations (1) to (3) to calculate the average parameters for each codend design. To avoid underestimating the confidence limits of the model parameters, which could otherwise occur when estimation is based on pooled data (Fryer 1991), we applied a method that uses a double bootstrapping technique to account for both within- and between-haul variation in selection processes (see Sistiaga et al. 2010, for details). This bootstrapping technique also takes into account the additional uncertainty arising from working on subsample data, as described by Eigaard et al. (2012). The overall selectivity parameters of the total process (i.e., the towing process followed by the haulback process: $L 50_{\text {total }}$ and $S R_{\text {total }}$ ) were estimated using the numerical method described in Sistiaga et al. (2010). Estimation of the $95 \%$ confidence limits (Efron 1982) for the average escapement and retention for all length classes was performed by calculating $e_{\text {tow }}(l), e_{\text {haul-back }}(l)$, and $r_{\text {total }}(l)$ according to equation (2) in each of the 10000 bootstrap resamplings used in the estimation method (Eigaard et al. 2012).

\subsection{Model evaluation}

The ability of the models to describe the average experimental data was evaluated by calculating the $p$-value, which expresses the likelihood of obtaining at least as large a deviation between the experimental data and the applied model by coincidence. Deviance statistics for the model (Wileman et al. 1996) compared to the number of degree of freedom $(d f)$ can be used to help judge the ability of a model to describe the experimental data: in general, the model deviance should not exceed df. If a model does not meet these criteria, it is necessary to determine whether the reason is the model's inability to describe the length-based structure of the data or whether it is simply a case of overdispersion in the data. For the type of analysis applied in this study, which involves calculating the fit statistic based on data that can be raised (in the case of subsampling in the experimental data), the fit statistics could well indicate lack of model fit. Lack of fit would mean that the applied model is not able to describe the structure in the experimental data. In particular, data that include high subsampling proportions could result in poor fit statistics even if the model has no structural problems. Residual plots that include both the experimental data and the model's prediction can be used to look for structural problems in a model's ability to describe experimental data. Wileman et al. (1996) provides additional information about how to apply the methods described above to evaluate the ability of a model to describe experimentally obtained selectivity data.

\subsection{Estimation of fractions below and above minimum landing size (MLS)}

This sequential selectivity model was also used to estimate the average length-integrated percentage of fractions below and above $M L S\left(M L S_{-}, M L S_{+}\right)$contained in the different compartments (cover tow, cover haul-back, codend). For a given species and haul, this was done by summing the number of individuals collected that were below and above $M L S$ in the different compartments. The data were then summed over hauls to obtain total numbers, and this sum was divided by the total 
Table 1. Operational conditions.

\begin{tabular}{|c|c|c|c|c|c|}
\hline & $\begin{array}{c}\text { Towing } \\
\text { duration }(\mathrm{h})\end{array}$ & $\begin{array}{l}\text { Depth } \\
\text { (m) }\end{array}$ & $\begin{array}{c}\text { Sea state } \\
\text { wave height } \\
(\mathrm{m})\end{array}$ & $\begin{array}{c}\text { (Haul-back) } \\
\text { duration (min) }\end{array}$ & $\begin{array}{c}\text { Towing } \\
\text { speed (knot) }\end{array}$ \\
\hline \multicolumn{6}{|l|}{ Standard codend } \\
\hline Avg. \pm SD & $3.50 \pm 0.75$ & $53 \pm 33$ & $1.4 \pm 0.8$ & $12.7 \pm 7.0$ & $2.6 \pm 0.1$ \\
\hline Range & $1.68-4.58$ & $31-135$ & $0.5-3.0$ & 9-33 & $2.5-2.8$ \\
\hline \multicolumn{6}{|l|}{$T 90$ codend } \\
\hline Avg. \pm SD & $3.54 \pm 0.81$ & $52 \pm 33$ & $1.3 \pm 0.8$ & $11.7 \pm 6.0$ & $2.6 \pm 0.1$ \\
\hline Range & $1.68-4.78$ & $31-135$ & $0.5-3.0$ & 9-33 & $2.5-2.8$ \\
\hline
\end{tabular}

Table 2. Average (avg.) catch and escape with standard deviation and range.

\begin{tabular}{cccccccc}
\hline & \multicolumn{3}{c}{ Standard codend $(\mathrm{kg})$} & & \multicolumn{3}{c}{ T90 codend $(\mathrm{kg})$} \\
\cline { 2 - 4 } & Escape towing & Escape haul-back & Codend towing & & Escape towing & Escape haul-back & Codend towing \\
\hline Avg. \pm SD & $224 \pm 185$ & $134 \pm 134$ & $361 \pm 146$ & & $274 \pm 192$ & $101 \pm 150$ & $261 \pm 234$ \\
Range & $27-561$ & $40-466$ & $91-466$ & & $17-742$ & $33-606$ & $21-861$ \\
\hline
\end{tabular}

numbers to obtain the average fraction. To obtain the percentage, we simply multiplied the result by 100 . Thus, the fractions escaping during towing $\left(P \_e_{\text {tow- }}, P \_e_{\text {tow }}\right)$ were estimated using the following formulae:

$$
\begin{aligned}
& P \_e_{\text {tow }}=100 \times \frac{\sum_{\text {hauls }}\left\{\sum_{l<M L S} n c t_{l}\right\}}{\sum_{\text {hauls }}\left\{\sum_{l<M L S}\left(n c t_{l}+n c h_{l}+n t_{l}\right)\right\}} \\
& P \_e_{\text {tow }}=100 \times \frac{\sum_{\text {hauls }}\left\{\sum_{l \geqslant M L S} n c t_{l}\right\}}{\sum_{\text {hauls }}\left\{\sum_{l \geqslant M L S}\left(n c t_{l}+n c h_{l}+n t_{l}\right)\right\}} .
\end{aligned}
$$

By replacing the $n c t$ in the nominator in the formulas above by $\mathrm{nch}_{1}$ and $\mathrm{nt}_{1}$ respectively, can the length-integrated fractions can be estimated for escape during the haul-back operation $\left(P \_e_{\text {haul-back- }}, P \_e_{\text {haul-back+ }}\right)$ and for retention in the codend $\left(P_{\text {-retained }}, P_{- \text {retained }}\right)$. To separately estimate the uncertainty in $P \_e_{\text {tow- }}, P \_e_{\text {tow }}, P \_e_{\text {haul-hack- }}, P_{-} e_{\text {haul-back }}, P_{\text {-retained }}$, and $\bar{P}_{\text {-retained }+}$ for each species considering both the effect of between-haul variation and that of the uncertainty related to within-haul variation, we used the double bootstrapping method described in Section 2.5 to estimate the "Efron percentile" 95 confidence limits for the estimated percentage fraction values.

\section{Results}

\subsection{Sea trials and mesh measurements}

A total of 16 hauls were conducted. The Minisampler did not function in one haul for each codend because it was not released. We removed these hauls from the analysis so that we could use the sequential selection model for the comparisons, which left us with 15 hauls for each codend. Catches were limited in the excluded hauls, and excluding them from the analysis resulted in only very minimal changes in selectivity estimates. Information on general operational conditions is given in Table 1. Towing duration was about 3.5 hours at a towing speed of 2.6 knots and depth ranged from 31-135 m. The haul-back duration was 9-12 min for 14 hauls, but due to difficult weather conditions with sea state up to $3 \mathrm{~m}$ wave height (Table 1), the haul-back durations were 26 and $33 \mathrm{~min}$ for the remaining 2 hauls. The Minisampler did not function in the 26 min haul-back haul, which explains the observed difference in average values. Table 2 lists the data for average codend catch, towing escapes, and haul-back escapes for 15 hauls of each codend. The average codend catch during towing was lower in the $T 90$ codend $(234 \mathrm{~kg})$ than in the standard codend (361 kg).

The mean mesh sizes with standard deviation for the standard and T90 codends were 97.7 (2.6) $\mathrm{mm}$ and 97.6 (2.9) $\mathrm{mm}$, respectively, before use when dry. The values were 96.4 (2.5) $\mathrm{mm}$ and 93.9 (2.7) $\mathrm{mm}$ midway through the experiment (after haul 8) when wet and 93.07 (2.6) $\mathrm{mm}$ and 94.2 (2.9) $\mathrm{mm}$ after the sea trials when wet. The average mesh sizes were 96.1 (3.0) $\mathrm{mm}$ and 94.9 (3.4) $\mathrm{mm}$ for the standard and $T 90$ codends, respectively. The mesh size of the two codends was almost identical at the beginning of the experiment. The measurements made halfway through the experiment indicated that the size of the knots on the $T 90$ had increased, thereby decreasing the mesh size slightly.

\subsection{Catches}

The species are divided by legal minimum landing size to provide a pooled estimate of numbers entering the codend, escaping during towing, escaping during haul-back (Table 3). Numbers retained and numbers caught are indicated (Fig. 3). The standard codend retained $83 \%$ of Norway lobster above MLS whereas the T90 codend retained 33\% (Table 3). The escape during towing was $24 \%$ and $10 \%$ for Norway lobster below and above $M L S$ respectively and $11 \%$ and $7 \%$ during haul-back but differences were not statistical significant (overlap in $95 \%$ confidence limits). In the $T 90$ codend, the similar escape was $64 \%$ and $52 \%$ during towing and $19 \%$ and $15 \%$ during haul-back with the first difference being statistically significant. The standard codend retained $65 \%$ below $M L S$ (discard) and $83 \%$ above $M L S$ and the T90 codend $17 \%$ and $33 \%$, respectively, and both differences where statistically significant. For plaice in the standard codend $49 \%$ under $M L S$ 
Table 3. Total numbers entering and percentage retained and escaped during towing and haul-back. Minimum landing size (MLS) is $40 \mathrm{~mm}$ cephalothorax length for Norway lobster, $27 \mathrm{~cm}$ for plaice and $30 \mathrm{~cm}$ for cod (in Kattegat). Confidence limits (95\%) are indicated in parenthesis.

\begin{tabular}{|c|c|c|c|c|c|c|c|c|}
\hline \multirow[b]{2}{*}{ Species } & \multicolumn{2}{|c|}{ Numbers entering } & \multicolumn{2}{|c|}{ Escape towing (\%) } & \multicolumn{2}{|c|}{ Escape haul-back (\%) } & \multicolumn{2}{|c|}{ Retained (\%) } \\
\hline & Standard & $T 90$ & Standard & $T 90$ & Standard & $T 90$ & Standard & $T 90$ \\
\hline \multicolumn{9}{|c|}{ Norway lobster } \\
\hline$<M L S$ & 22462 & 18325 & $24(14-38)$ & $64(49-76)$ & $11(6-18)$ & $19(9-32)$ & $65(48-79)$ & $17(10-25)$ \\
\hline$\geqslant M L S$ & 4527 & 3537 & $10(4-22)$ & $52(29-68)$ & $7(2-15)$ & $15(6-30)$ & $83(68-92)$ & $33(17-54)$ \\
\hline \multicolumn{9}{|l|}{ Plaice } \\
\hline$<M L S$ & 2875 & 3164 & $49(35-61)$ & $45(34-54)$ & $23(11-38)$ & $12(4-22)$ & $28(21-36)$ & $43(36-51)$ \\
\hline$\geqslant M L S$ & 258 & 294 & $0(0-4)$ & $1(0-4)$ & $0(0-0)$ & $1(0-3)$ & $100(96-100)$ & $98(94-100)$ \\
\hline \multicolumn{9}{|l|}{ Cod } \\
\hline$<M L S$ & 503 & 281 & $23(12-33)$ & $32(13-52)$ & $33(22-44)$ & $46(29-62)$ & $44(32-57)$ & $22(7-43)$ \\
\hline$\geqslant M L S$ & 254 & 237 & $3(0-7)$ & $2(0-10)$ & $7(3-35)$ & $4(1-19)$ & $90(65-96)$ & $94(72-99)$ \\
\hline
\end{tabular}

escaped during towing and $23 \%$ during haul-back (Table 3), but differences were not statistically significant. In the $T 90$, the escapes under $M L S$ were $45 \%$ and $12 \%$ during towing and haul back, respectively, and the difference was statistically significant. No plaice above $M L S(27 \mathrm{~cm})$ in the standard codend escaped and $1 \%$ escaped during towing and haul-back in the $T 90$ codend. The $T 90$ codend retained $43 \%$ plaice below $M L S$ and the standard codend retained $28 \%$, with this difference being close to statistically significant. The number of cod caught during this study was relatively low (Table 3 ). The standard codend caught more cod below MLS than the T90 codend. Inspection of individual hauls indicated that this was a general trend irrespective of the side of the trawl rig on which the codend was fished. In the standard codend, $23 \%$ of cod below $M L S$ (30 cm in Kattegat) and 3\% above MLS escaped during towing and $32 \%$ below $M L S$ and $7 \%$ above $M L S$ during haul-back. In the $T 90$ codend, $32 \%$ of cod below $M L S$ and $2 \%$ above $M L S$ escaped during towing and $46 \%$ below $M L S$ and $4 \%$ above $M L S$ escaped during haul-back. No differences were statistically significantly for cod.

\subsection{Selectivity analysis}

Estimated selectivity parameters together with fit statistics are given (Table 4), and the selection curves are shown (Fig. 3). The fit statistics ( $p$-value) for Norway lobster in both codends indicate that the model was not able to describe the data well $(p<0.0001)$. The data for Norway lobster were based on subsampling, and the poor fit statistics could be due to the calculation based on the raised data (see method section). To investigate this possibility, we inspected the partial residual plots for retention in the total process $\left(r_{\text {total }}(l)\right)$, for escapement during towing $\left(e_{\text {tow }}(l)\right)$, and for escapement during the haul-back operation $\left(e_{\text {haul-back }}(l)\right)$. We found no indication of structural problems for any of the processes for either codend. Data in relation to the selection curves do not indicate a structural problem (Fig. 3). Thus, we were confident in applying the results from the model (Eq. (2)) to describe the selection processes of Norway lobster in the length range of 25 to $48 \mathrm{~mm}$, in which most individuals were found (Fig. 3). For this size range, escape during towing was significantly higher (no overlap in confidence limits) in the $T 90$ codend than in the standard codend (Fig. 3), but there was no significant difference between codends in escape during haul-back. Significant escape likelihood (confidence limits clear of $x$-axis) during haul-back was found with both codends. The confidence limits for the selectivity parameters of Norway lobster were wide (Table 4), but the $L 50_{\text {total }}$ was significantly higher for the $T 90$ codend $(52.3 \mathrm{~mm})$ compared with the standard codend $(16.2 \mathrm{~mm})$. Other selection parameters did not differ significantly between codends. For both codends, the $L 50_{\text {total }}$ was outside the 25 to $48 \mathrm{~mm}$ range. The retention rate in the 25 to $48 \mathrm{~mm}$ range was significantly lower for the $T 90$ codend (95\% confidence limits, Fig. 3).

For plaice, the data were well modelled for the standard codend, as indicated by the fit statistics, but this was not the case for the $T 90$ codend ( $p=0.0047$, Table 4). However, eliminating the data from the only haul for which subsampling was used resulted in acceptable fit statistics $(p=0.29)$. This result suggests that the cause of the poor fit statistics was the use of raised data rather than the model's inability to describe the data. This premise is further supported by inspecting the modelled curves compared with the experimental data (Fig. 3). The $C_{t o w}$ value was 0.67 and 0.86 for the standard and $T 90$ codends respectively, and significantly lower than 1.0 (Table 4), which means that not all individuals were able to make an escape attempt during towing. Further, an attempt to fit a model without $C_{\text {tow }}$ resulted in a clear structure in the residuals, demonstrating the need to consider this parameter. This value did not differ significantly between the standard and $T 90$ codends. The $L 50_{\text {total }}$ was significantly higher for the standard codend $(21.9 \mathrm{~cm})$ compared with that of the $T 90$ codend $(20.5 \mathrm{~cm})$, but the difference in the estimated parameters is limited (Table 4). This difference in $L 50_{\text {total }}$ is also indicated (albeit not very clearly) by the missing overlap in confidence limits of the retention curves (Fig. 3) around L50. The estimated values of $L 50_{\text {total }}$ for both designs were thus considerably below the $M L S(27 \mathrm{~cm})$. There was no significant difference in selection parameters (Table 4) or escape curves (Fig. 3) during towing and haul-back between the two codends. The escape likelihood during haul-back was significant (confidence limits clear of $x$-axis) in both codends.

For cod, the fit statistics indicate that the data for both the standard and $T 90$ codends were well described by the model $(p<0.05)$. Plotting the residuals did not indicate any structure in the deviation between data and curves based on the model. There were some larger cod with a relatively low retention value, but removing these few individuals from the model 

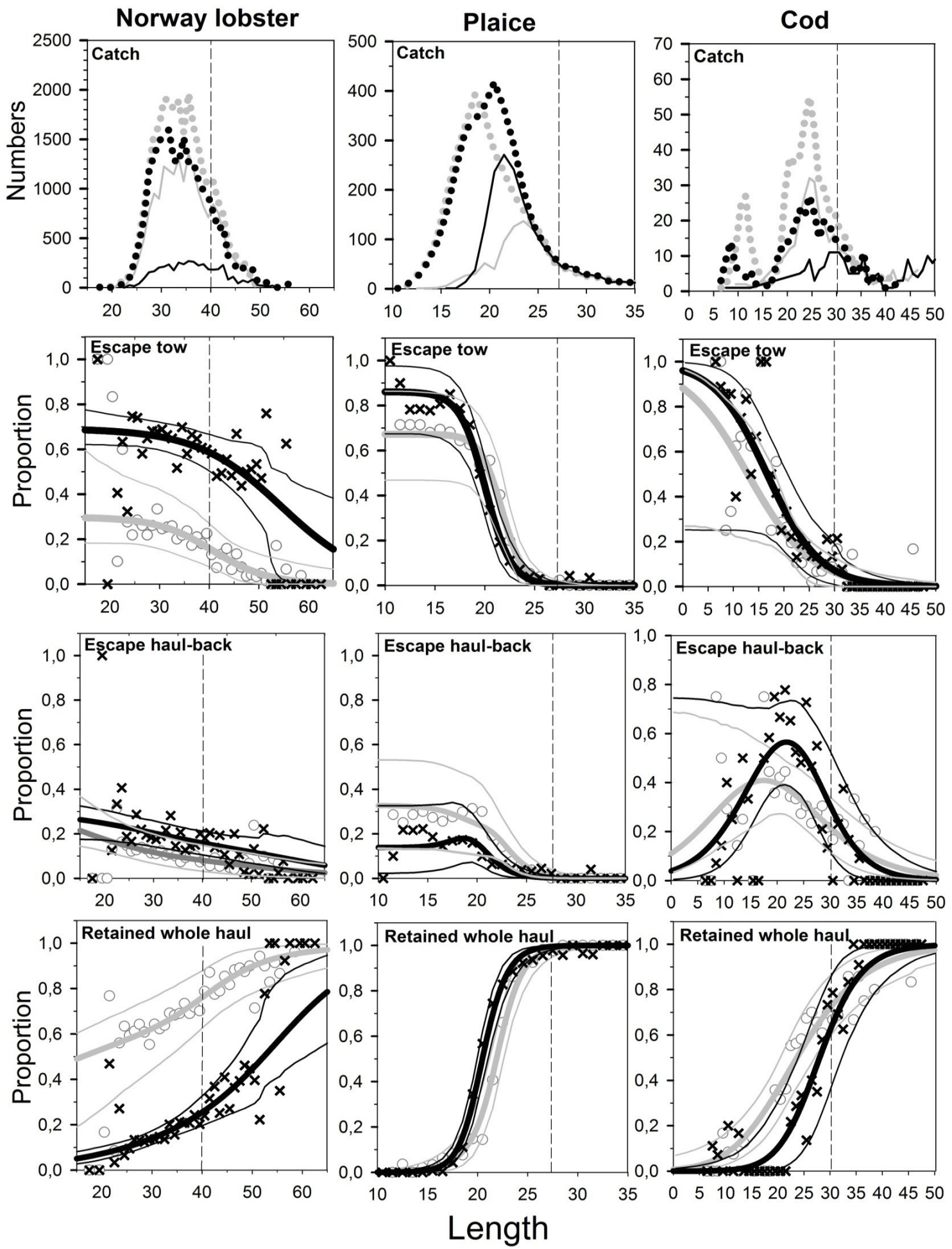

Fig. 3. Catch in numbers, proportion escaped during towing and haul-back, and proportion retained. Results are shown for Norway lobster (left column), plaice (middle), and cod (right). The standard codend data are shown in grey and the T90 codend data are shown in black. The top row of panels shows total catches in numbers (codend and covers, dotted line) and the codend catch. Escape curves for towing, haul-back, and total retention (proportion retained) are shown in the three lower rows. The thick lines indicate lines predicted by models and the thin lines show the 95\% confidence intervals. Circles (O standard netting) and crosses ( $\times T 90)$ indicate retention points for each length class. The dotted vertical line indicates minimum landing size $(M L S)$. Length in $\mathrm{mm}$ cephalothorax length for Norway lobster, and $\mathrm{cm}$ for plaice and cod. 
Table 4. The estimated selectivity parameters $L 50$ (50\% retention length), $S R$ (selection range), $C$ (contact), $p$-value, deviance. $L 50$ and $S R$ in $\mathrm{mm}$ cephalothorax length for Norway lobster, and in $\mathrm{cm}$ for plaice and cod.

\begin{tabular}{|c|c|c|c|c|c|c|}
\hline & \multicolumn{2}{|c|}{ Norway lobster } & \multicolumn{2}{|c|}{ Plaice } & \multicolumn{2}{|c|}{ Cod } \\
\hline & Standard & $T 90$ & Standard & $T 90$ & Standard & $T 90$ \\
\hline$L 50_{\text {total }}$ & $16.2(7.1-33.7)$ & $52.3(42.2-66.2)$ & $21.9(21.2-22.6)$ & $20.5(20.0-21.0)$ & $23.7(20.6-27.0)$ & $28.0(24.0-32.2)$ \\
\hline$S R_{\text {total }}$ & $49.3(20.9-56.2)$ & $23.4(4.1-56.5)$ & $2.9(1.9-4.0)$ & $2.7(2.1-3.3)$ & $14.1(8.6-9.6)$ & $8.8(4.5-13.5)$ \\
\hline$C_{\text {tow }}$ & $0.30(0.19-1.0)$ & $0.69(0.55-1.00)$ & $0.67(0.47-0.86)$ & $0.86(0.66-0.98)$ & $1.00(0.27-1.00)$ & $1.00(0.23-1.00)$ \\
\hline$L 50_{\text {tow }}$ & $40.7(0.1-46.1)$ & $54.5(35.4-61.4)$ & $21.7(20.3-22.7)$ & $20.1(19.4-21.0)$ & $12.9(5.1-25.8)$ & $16.7(13.5-31.0)$ \\
\hline$S R_{\text {tow }}$ & $12.4(4.1-51.8)$ & $18.6(0.1-83.3)$ & $2.4(0.94-4.16)$ & $2.9(2.0-3.9)$ & $14.0(2.0-24.0)$ & $11.5(1.0-15.0)$ \\
\hline L50 haul-back & $0.45(0.1-19.2)$ & $34.4(21.6-47.9)$ & $20.3(18.4-21.5)$ & $18.7(16.6-19.7)$ & $20.8(15.9-24.8)$ & $27.0(22.6-31.5)$ \\
\hline$S R_{\text {haul-back }}$ & $38.7(18.6-53.0)$ & $25.9(14.8-65.7)$ & $3.7(2.4-5.4)$ & $3.0(1.9-5.0)$ & $16.9(10.7-26.1)$ & $9.2(4.5-15.8)$ \\
\hline$p$-value & $<0.0001$ & $<0.0001$ & 0.1198 & 0.0047 & 0.9997 & 0.9985 \\
\hline Deviance & 374.0 & 582.2 & 76.4 & 105.7 & 92.4 & 96.3 \\
\hline $\begin{array}{l}\text { Degree of } \\
\text { freedom }\end{array}$ & 73 & 79 & 63 & 71 & 143 & 141 \\
\hline
\end{tabular}

resulted in only a minor change. The $C_{\text {tow }}$ value was estimated to be 1.0 for both codends, but the confidence limits were wide (Table 4). The standard and $T 90$ codends were not very selective for cod during towing $(12.9 \mathrm{~cm}$ and $16.7 \mathrm{~cm}$ respectively), but the selectivity increased during haul-back $(20.8 \mathrm{~cm}$ and $27.0 \mathrm{~cm}$ respectively) (Table 4, Fig. 3). This was particularly true for the $T 90$ codend. There were no significant differences (overlap of $95 \%$ confidence limits) between the selectivity parameters of the two codends during towing and haul-back. The escape likelihood during haul-back was significant (confidence limits clear of $x$-axis) in both codends. Most small cod escaped during towing, whereas individuals escaping during haul-back were larger (Fig. 3). The $L 50_{\text {total }}$ was higher for the T90 codend $(28.0 \mathrm{~cm})$ compared with the standard codend $(23.7 \mathrm{~cm})$, but overlap of the $95 \%$ confidence limits indicates that this difference was not significant (Table 4). For the standard codend, the $L 50_{\text {total }}$ was significantly smaller than the $M L S(30 \mathrm{~cm})$, which was not the case for the T90 codend (Fig. 3). The L50 of both codends during towing was more than $10 \mathrm{~cm}$ lower than $L 50_{\text {total }}$, but the confidence limits were wide (Table 4).

\section{Discussion}

Our experiments clearly demonstrated that use of more advanced new technology (Minisamplers) can provide additional information about selective properties of the tested gears, which in turn influences the interpretation of the results. The method we used in this experiment made it possible to compare codends fished simultaneously, thereby limiting the uncertainty caused by between-haul variations in the fishing process and making the comparisons stronger.

The results demonstrated that there was a considerable escape of individuals below $M L S$ during haul-back for three rather different species for both the $T 90$ codend and the standard codend, with no statistically significantly difference that would suggest a benefit from choosing one of the codends over the other. This level of escape was likely caused by individuals not making escape attempts or insufficient escape attempts during towing or entering the codend very late in the fishing process. The escape rate during haul-back was very high compared with that during towing, with a substantial escapes over a very limited period (12 min on average). It is likely that the reduced speed and drag in a new direction during haul-back alter the environment inside the codend and generate a lower flow and a different net geometry that will trigger this fish behaviour. When fish and Norway lobster escape during haulback rather than during towing they are probably be exposed to more stress and physical injury. The latter is particularly the case in fisheries where Norway lobster is a target species since the catch will be exposed to the exoskeletons of this crustacean and other invertebrates often taken as bycatch. Cod will suffer from decompression whereas Norway lobster may suffer from damage to their retinas (Shelton et al. 1985; Gaten 1988) and additional physiological stress (Harris and Andrews $2005 \mathrm{a}, 2005 \mathrm{~b})$ that can be caused by exposure to the low salinity surface layers found in the Kattegat and Skagerrak area (Harris and Ulmestrand 2004). Close to and at the surface, individuals will be subjected to sea bird predation (Votier et al. 2004). Some of the escapes will occur in the beginning of the haul-back phase where the probability of survival is likely to be higher than for late escape. Escapement during haul-back is likely to be influenced by haul-back duration, sea state and codend catch weight (Madsen et al. 2008). Our results suggest that it is still important to develop selective fishing gears that are better to let fish escape immediately when entering the codend during towing. Any late escape will increase the possibility of additional mortality.

The modelling approach used in the present paper made it possible to describe in detail the escape process during towing and haul-back and to estimate the proportion of fish that came in contact with the netting. We found that not all plaice came into contact with the codend netting during towing. The selectivity (L50) of plaice was lower for the $T 90$ netting than for the standard netting. The likely explanation is that the diamond shaped standard mesh opening better fits the shape of plaice than the $T 90$ mesh opening.

The $T 90$ codend retained fewer cod below $M L S$ and had a higher $L 50$ for the total tow for towing and haul-back than the standard codend. However, this difference was not statistically significant, probably because the statistical power was low due to the low number of individuals caught (which produced wide confidence limits). Wienbeck et al. (2011) recently reported an improved $L 50$ for Baltic cod by using $T 90$ meshes, and this could likely have been the case here if more cod had been caught. Most cod in this experiment escaped during haul-back in both codends. A higher escape rate was observed for cod in 
the size range from 20 to $30 \mathrm{~cm}$. A possible explanation is that decreased tension in the netting during haul-back will open the meshes in the $T 90$ codend, thereby providing a more optimal opening through which cod can escape.

We used newly-made codends for the present experiment. However, the $T 90$ effect (a more open mesh) might be reduced after the net has been in use for some time (Suuronen et al. 2007) because the knots change shape by being stretched in a new direction. The mesh measurements at the end of the experiment revealed that the knots of the $T 90$ netting had changed, which influenced the mesh measures. The twine characteristics, such as thickness and stiffness, also will likely influence the $T 90$ effect. Stiffer twine might open the mesh more and the size of the knot relative to the mesh size will decrease with decreasing twine thickness; these factors might reduce the $T 90$ effect. This scenario is opposite to the expected effect of standard meshes, where the selectivity will decrease with increasing twine thickness (Lowry and Robertson 1995; Sala et al. 2007) and stiffness (Madsen et al. 1998; Tokac et al. 2004). These issues clearly need to be investigated because twine thickness often is included in technical regulations because it is related to the expected effect of standard meshes. A theoretical study suggests that codend catch weight also affects the shape of the codend and thereby the mesh opening of standard meshes (Herrmann 2005). At higher catch weights than those obtained in the present study, the performance of the $T 90$ netting might also change.

As observed elsewhere (Frandsen et al. 2009), the L50 of cod, plaice and Norway lobster in the standard $90 \mathrm{~mm}$ codend currently used in the Kattegat-Skagerrak area is low in relation to the $M L S$, which leads to high discard rates, particularly when considering that the selectivity during towing is considerably lower for cod and Norway lobster compared to the total selectivity traditionally estimated. The use of a $120 \mathrm{~mm}$ square mesh panel does not provide any major improvement of the selectivity for these three species (Frandsen et al. 2009), and additional means are clearly needed to improve it. Considering the high release of Norway lobster and cod during haul-back, the tendency towards a general loss of Norway lobster above $M L S$, and the lack of effect on plaice, the $T 90$ codend does not appear to be an optimal solution for the Norway lobster-directed fishery in the KattegatSkagerrak area or the many other areas where comparable problems exist (Catchpole and Revill 2008). Increasing retention of Norway lobster above $M L S$ by reducing the T90 mesh size would also cause increased catches of cod and plaice below $M L S$.

Meshes that have a constant mesh opening combined with an optimal mesh shape, identified from theoretical work (Herrmann et al. 2009; Frandsen et al. 2010a) and experimental sea trials (Frandsen et al. 2010b; Frandsen et al. 2011), seem to have higher potential than the $T 90$ meshes to improve size selectivity for cod and Norway lobster. The drawback of such solutions is that they can be more complex in relation to gear design. Additionally, efficient selective devices are needed to achieve a better selectivity of cod. These can be constructed based on behavioural differences (Madsen et al. 2010) or mechanical sorting (Valentinsson and Ulmestrand 2008; Frandsen et al. 2009).
Acknowledgements. We thank Mogens Andersen (SINTEF), Kurt Hansen (SINTEF), Jan Jensen, the crew of the Mette-Amalie, and anonymous referees for useful comments. This work was conducted as part of the SELTRA project, which was carried out with the financial support of the European Union and Danish Ministry of Food, Agriculture and Fisheries.

\section{References}

Akaike H., 1974, A new look at the statistical model identification. IEEE Trans. Automat. Contr. AC-19, 716-23.

Catchpole T.L., Revill A.S., 2008, Gear technology in Nephrops trawl trawl ?sheries. Rev. Fish. Biol. Fish. 18, 17-31. Efron, B., 1982, The jackknife, the bootstrap and other resampling plans. SIAM Monograph No. 38, CBSM-NSF.

Eigaard O.R., Herrmann B., Nielsen R., 2012, Influence of grid orientation and time of day on grid sorting in a small-meshed trawl fishery for Norway pout (Trisopterus esmarkii). Aquat. Living Resour. 25, 15-26.

Feekings J., Bartolino V., Madsen N., Catchpole T., 2012, Fishery discards: factors affecting their variability within a demersal trawl fishery. PLoS One 7(4), e36409.

Fonteyne R., Buglioni G., Leonori I., O’Neill F.G., 2007, Review of mesh measurement methodologies. Fish. Res. 85, 279-284.

Frandsen R.P., Herrmann B., Madsen N., 2010a, A simulation-based attempt to quantify the morphological component of size selection of Nephrops norvegicus in trawl codends. Fish. Res. 101, 156-167.

Frandsen R.P., Herrmann B., Madsen N., Krag L.A., 2011, Development of a codend concept to improve size selectivity of Nephrops (Nephrops norvegicus) in a multi-species fishery. Fish. Res. 111, 116-126.

Frandsen R.P., Madsen N., Krag L.A., 2010b, Selectivity and escapement behaviour of five commercial species in a square mesh and a diamond mesh codend. ICES J. Mar. Sci. 67, 1721-1731.

Frandsen R.P., Holst R., Madsen N., 2009, Evaluation of three levels of selective devices relevant to management of the Danish Kattegat-Skagerrak Nephrops fishery. Fish. Res. 97, 243-252.

Fryer R.J., 1991, A model of the between-haul variation in selectivity. ICES. J. Mar. Sci. 48, 281-290.

Grimaldo E., Larsen R.B., Sistiaga M., Madsen N., Breen M., 2009, Selectivity and escape percentages during three phases of the towing process for codends fitted with different selection systems. Fish. Res. 95, 198-205.

Harris R.R., Andrews M.B., 2005a, Physiological changes in the Norway lobster Nephrops norvegicus (L.) escaping and discarded from commercial trawls on the West Coast of Scotland. 1. Body fluid volumes and haemolymph composition after capture and during recovery on the seabed. J. Exp. Mar. Biol. Ecol. 320, 179193.

Harris R.R., Andrews M.B., 2005b, Physiological changes in the Norway lobster Nephrops norvegicus (L.) escaping and discarded from commercial trawls on the West Coast of Scotland. II. Disturbances in haemolymph respiratory gases, tissue metabolites and swimming performance after capture and during recovery. J. Exp. Mar. Biol. Ecol. 320, 195-210.

Harris R.R., Ulmestrand M., 2004, Discarding Norway lobster (Nephrops norvegicus L.) through low salinity layers - mortality and damage seen in simulation experiments. ICES J. Mar. Sci. $61,127-139$. 
Herrmann B., 2005, Effect of catch size and shape on the selectivity of diamond mesh cod-ends: II Theoretical study of haddock selection. Fish. Res. 71, 15-26.

Herrmann B., Priour D., Krag L.A., 2007, Simulation based study of the combined effect on cod-end size selection for round fish of turning mesh $90^{\circ}$ and reducing the number of meshes in the circumference. Fish. Res. 84, 222-232.

Herrmann B., Krag L.A., Frandsen R.P., Madsen N., Lundgren B., Stæhr K.J., 2009, Prediction of selectivity from morphological conditions: Methodology and a case study on cod (Gadus morhua). Fish. Res. 97, 59-71.

ICES, 2010, Report of the study group on Turned $90^{\circ}$ codend selectivity, focusing on Baltic cod selectivity (SGTCOD). ICES CM 2010/FTC:05.

ICES, 2011, Report of the study group on Turned $90^{\circ}$ codend selectivity, focusing on Baltic cod selectivity (SGTCOD), 4-6 May 2011, IMR, Reykjavik, Iceland. ICES CM 2011/SSGESST:08.

Krag L.A., Frandsen R.P., Madsen N., 2008, Evaluation of a simple means to reduce discard in the Kattegat-Skagerrak Nephrops (Nephrops norvegicus) fishery: Commercial testing of different codends and square-mesh panels. Fish. Res. 91, 175-186.

Lowry N., Robertson J.H.B., 1995, The effect of twine thickness on cod-end selectivity of trawls for haddock in the North Sea. Fish. Res. 26, 353-363.

Madsen N., 2007, Selectivity of fishing gears used in the Baltic Sea cod fishery. Rev. Fish. Biol. Fish. 17, 517-544.

Madsen N., Hansen K.E., Moth-Poulsen T., 2001, The kite cover: a new concept for covered codend selectivity studies. Fish. Res. 49, 219-226.

Madsen N., Hansen K.E., Frandsen R.P., Krag L.A., 2012, Development and test of a remotely operated Minisampler for discrete trawl sampling. Fish. Res. 123-124, 16-20.

Madsen N., Moth-Poulsen T., Lowry N., 1998, Selectivity experiments with window codends fished in the Baltic Sea cod (Gadus morhua) fishery. Fish. Res. 36, 1-14.

Madsen N., Skeide R., Breen M., Krag L.A., Huse I., Soldal A.V., 2008, Selectivity in a trawl codend during haul-back operation An overlooked phenomenon. Fish. Res. 91, 168-174.
Madsen N., Frandsen R.P., Holst R., Krag L.A., 2010, Development of new concepts for escape windows to minimise cod catches in Norway lobster fisheries. Fish. Res. 103, 25-29.

Madsen N., Valentinsson D., 2010, Use of selective devices in trawls to support recovery of the Kattegat cod stock: a review of experiments and experience. ICES J. Mar. Sci. 67, 2042-2050.

Manly B.F.J., 1997, Randomization, Bootstrap and Monte Carlo methods in biology - Texts in statistical science. Chapman \& Hall.

Millar R.B., 1993, Incorporation of between-haul variation using bootstrapping and nonparametric estimation of selection curves. Fish. Bull. 91, 564-572.

Sala A., Lucchetti A., Buglioni G., 2007, The influence of twine thickness on the size selectivity of polyamide codends in a Mediterranean bottom trawl. Fish. Res. 83, 192-203.

Shelton P.M., Gaten E., Chapman C.J., 1985, Light and retinal damage in Nephrops norvegicus (L.) (Crustacea). Proc. R. Soc. Lond. B 226, 217-236.

Sistiaga M., Herrmann B., Grimaldo E., Larsen R.B., 2010, Assessment of dual selection in grid based selectivity systems. Fish. Res. 105, 187-199.

Tokac A., Ozbilgin H., Tosunoglu Z., 2004, Effect of PA and PE material on codend selectivity in Turkish bottom trawl. Fish. Res. 67, 317-327.

Valentinsson D., Ulmestrand M., 2008, Species-selective Norway lobster trawling: Swedish grid experiments. Fish. Res. 90, 109117.

Votier S.C., Furness R.W., Bearhop S., Crane J.E., Caldow R.W.G, Catry P., Ensor K., Hamer K.C., Hudson A.W., Kalmbach E., Klomp N.I., Pfeiffer S., Phillips R.A., Prieto I., Thompson D.R., 2004, Changes in fisheries discard rates and seabird communities. Nature 427, 727-730.

Wienbeck H., Herrmann B., Moderhak W., Stepputtis D., 2011, Effect of netting direction and number of meshes around on size selection in the codend for Baltic cod (Gadus morhua). Fish. Res. 109, 80-88.

Wileman D.A., Ferro R.S.T., Fonteyne R., Millar R.B. (eds.), 1996, Manual of methods of measuring the selectivity of towed fishing gears. ICES Coop. Res. Rep. No. 215. 